\title{
Variation of Particle Size and Pretreatment Temperature to the Crystallinity of Leucaena Leucocephala
}

\author{
Nor Sharliza Mohd Safaai, Muhammad Izzudin Ibrahim, Amizon Azizan and Habsah Alwi \\ Universiti Teknologi MARA, Malaysia
}

\begin{abstract}
This study was conducted in order to determine the effect of different particle size and pretreatment temperature to the crystallinity of leucaena leucocephala. The leucaena was pretreated by ionic liquid [1-ethyl-3 methylimidazolium acetate [Emim]Ac. There were three different particle sizes that have been tested in this experiment; less than $0.3 \mathrm{~mm}, 0.5 \mathrm{~mm}$ and $0.7 \mathrm{~mm}$. In the other hand, the pretreatment temperature tested were $30^{\circ} \mathrm{C}$, $60^{\circ} \mathrm{C}$ and $90^{\circ} \mathrm{C}$. The effect of particle size and pretreatment temperature to the crystallinity of leucaena was investigated by using X-Ray Diffraction (XRD) and Scanning Electron Microscopy (SEM). The crystallinity index of the sample represents the percentage of crystalline materials. A lower in the cristallinity index indicated that the material has lower crystillinity, hence give more benefit to the cellulose hydrolysis. From XRD analysis, it shows that the cristallinity index of leucaena decreased with decreasing particle size and increasing pretreatment temperature. SEM analysis also shows that the structure of leucaena has more irregular, porous and destroyed structure with decreasing particle size and increasing pretreatment temperature. Thus, the result from this experiment shows that the smaller particle size and higher pretreatment temperature would provide a more accessible surface area to enhance the cellulose hydrolysis.
\end{abstract}

\section{Introduction}

An increase in world population and living standards caused the rise of the demand for energy. By 2025, world energy demand is predicted to grow more than $50 \%$ due to high demand from several rapidly developing countries [1]. However, the high demand of fossil fuels with the lack of sources has caused the increased of it prices. The researcher found the new liquid fuels that can replace fossil fuels called biofuels. Unlike fossil fuels, biofuels are produced from biomass. Biomass is the biological material from living or recently living organism such as wood, waste materials, gases and alcohol fuels [2]. Cellulosic biomass is the structural component of plants including complex sugars that cannot directly be used for fermentation substrates. There are three main components that make up the cell walls that form the tissue structure of cellulosic biomass which are cellulose, hemicellulose and lignin [3].

Cellulose is a linear polymer consists of long chain made up of glucose that linked together by $\beta-1,4$ glycosidic bonds. Cellulose chains are linked together by strong hydrogen bonds that make cellulose highly crystalline polymer [4]. Hemicellulose is an amorphous chain of polysaccharides containing sugar residues and it protects the cellulose fibrils from enzymatic deconstruction [5]. Lignin without sugar-based structure is an amorphous polymer made up of aromatic derivatives [6].

The production of biofuels (Bioethanol) from biomass must go through four main process which are pretreatment, enzyme hydrolysis, fermentation and distillation. The complex structure of lignocellulose biomass cause it difficult to be hydrolyzed and leads to decrease the sugar yield in cellulose hydrolysis. Pretreatment is the most important step in helping enzyme hydrolysis and fermentation steps to maximize the desired product. The goals of pretreatment process are to open up the biomass structure, increase accessible surface area, reduce the cellulose crystallinity and increase the sugar yield in cellulose hydrolysis [7].

Pretreatment are usually classified into four categories which are physical, chemical, physicochemical and biological. It was found that, physical and chemical pretreatment become a conventional pretreatment technologies among the four pretreatment methods [8].

Physical pretreatment involve the size reduction of lignocellulose materials by a combination of chipping, grinding and milling process to reduce the cellulose crystallinity. Chemical pretreatment is classified into alkaline, acid, ionic liquids and wet oxidation. Lately, ionic liquids (IL) have received much attention due to its ability to dissolve various types of biomass. A study by [9] reported that a glucose yield over $90 \%$ could be obtained after pretreatment of energy cane bagasse by using [EMIM]Ac. In other study by [10] reported that 
[EMIM]Ac is the most efficient among six ionic liquid as it significantly enhanced bagasse enzymatic scarification rate and yield. Furthermore, the low vapor pressure of IL makes its more than $99 \%$ recoverable, thus reducing the solvent costs.

Crystallinity can be defined as the degree of structural order in a solid. The degree of crystallinity is used to monitor the level of degradation structure of the material. The effect of particle size and pretreatment temperature to the crystallinity of leucaena was investigated by using X-Ray Diffraction (XRD) and Scanning Electron Microscopy (SEM). From the graph by XRD analysis, the percentage of the cristallinity index can be calculated. SEM is used to monitor the surface structure changes of leucaena before and after pretreatment [11].

\section{Methodology}

\subsection{Sample preparation of leucaena}

The leucaena stem was grinded by using grinder machine. The grinded leucaena was sieving into three different particle sizes which are less than $0.3 \mathrm{~mm}, 0.5 \mathrm{~mm}$ and 0.7 $\mathrm{mm}$ by using sieve shaker.

\section{2 lonic liquid pretreatment}

In order to determine the effect of different particle size and pretreatment temperature to the crystallinity of leucaena, three different particle sizes which are less than $0.3 \mathrm{~mm}, 0.5 \mathrm{~mm}$ and $0.7 \mathrm{~mm}$ were used. $0.05 \mathrm{~g}$ sample of leucaena with particle size $0.5 \mathrm{~mm}$ was mixed with $1 \mathrm{ml}$ of $100 \%$ ionic liquid ([Emim]Ac) in a $1.5 \mathrm{ml}$ centrifugal tube. The solution was heated and shacked by using biological shaker at the temperature of $90^{\circ} \mathrm{C}$ for 3 hour and $1800 \mathrm{rpm}$ shake speed. After cooled at room temperature, the liquid was separated from the precipitated material by using centrifuge at $10000 \mathrm{rpm}$, 10 minutes and $4^{\circ} \mathrm{C}$. The precipitated material was then washed thoroughly with distilled water until no remaining IL solution and dried in an oven at $60^{\circ} \mathrm{C}$ for 24 hours. The sample was analyzed by using X-Ray Diffraction (XRD) and Scanning Electron Microcopy (SEM). For the different particle size as manipulated variable, the pretreatment was repeated by using different particle size (less than $0.3 \mathrm{~mm}$ and $0.7 \mathrm{~mm}$ ) while as pretreatment temperature become manipulated variable, the pretreatment was repeated by using different temperature $\left(30^{\circ} \mathrm{C} \& 60^{\circ} \mathrm{C}\right)$.

\subsection{Ammonia pretreatment}

For ammonia pretreatment, three different particle sizes which are less than $0.3 \mathrm{~mm}, 0.5 \mathrm{~mm}$ and $0.7 \mathrm{~mm}$ were used. $0.05 \mathrm{~g}$ sample of leucaena with particle size $0.5 \mathrm{~mm}$ was mixed with $1 \mathrm{ml}$ of $25 \%$ ammonia hydroxide solution in a $1.5 \mathrm{ml}$ centrifugal tube. The solution was heated and shacked by using biological shaker at the temperature of $30^{\circ} \mathrm{C}$ for 3 hour and $1800 \mathrm{rpm}$ shake speed. After cooled at room temperature, the liquid was separated from the precipitated material by using centrifuge at $10000 \mathrm{rpm}, 10$ minutes and $4^{\circ} \mathrm{C}$. The precipitated material was then washed thoroughly with distilled water until no remaining ammonia solution and dried in an oven at $60^{\circ} \mathrm{C}$ for 24 hours. The sample was analyzed by using X-Ray Diffraction (XRD) and Scanning Electron Microcopy (SEM).

\subsection{Ray diffraction (XRD) and scanning electron microscopy (SEM) analysis}

In order to determine the crystallinity index of untreated and pretreated samples of leucaena, the samples were analyzed by using XRD. The samples were analyzed from $4^{\circ}$ to $45^{\circ}$ with speed angle $2^{\circ}$ per minute at $40 \mathrm{kV}$ and $40 \mathrm{~mA}$. Besides, the morphology of untreated and pretreated samples of leucaena was examined by using SEM. The solid samples were mounted on the aluminum sample stubs with double sided carbon tape. SEM images were respectively taken at $200 \times$ magnification with SEM instrument operated at $5 \mathrm{kV}$ to $15 \mathrm{kV}$ accelerating voltage.

\section{Results and discussion}

This experiment was conducted in order to identify the effect of different temperature and particle size on the crystalline of leucaena leucocephala. Three different pretreatment temperature apply in this experiment were $30^{\circ} \mathrm{C}, 60^{\circ} \mathrm{C}$ and $90^{\circ} \mathrm{C}$ while three different particle size used were less than $0.3 \mathrm{~mm}, 0.5 \mathrm{~mm}$ and $0.7 \mathrm{~mm}$.

In order to understand the effect of different temperature and particle size on the crystalline structure of leucaena, X-Ray Diffraction (XRD) and Scanning Electron Microscopy (SEM) were used for analyzing. XRD analysis was executed to determine the crystallinity of leucaena before and after pretreatment. From the result obtained, the percentage of the crystallinity index could be calculated. In other hand, SEM was utilized to monitor the surface structure changes of leucaena before and after pretreatment.

A lower in the crystallinity index indicated that the material has lower crystillinity. The lower the cristallinity index in leucaena will give benefit to the cellulose hydrolysis.

\subsection{Effect of different particle size to the crystallinity of leucaena}

Result of XRD analysis for untreated and IL pretreated by using different particle size were shown in Fig. 1. Based on Fig. 1, the scattered intensity at the main peak for cellulose at $2 \theta\left(I_{002}\right)$ and the minimum intensity between the main and secondary peaks $\left(I_{a m}\right)$ for each sample may be measured. Then, the crystallinity index for each sample could be calculated by using equation 1 .

$$
\mathrm{CrI}=\frac{100 \times\left(\mathrm{I}_{002}-\mathrm{I}_{\mathrm{am}}\right)}{\mathrm{I}_{002}}
$$

where, $\quad \operatorname{CrI}=$ Crystallinity index (\%) 


$$
\begin{aligned}
& I_{002}=\text { The scattered intensity at the main peak } \\
& \text { for cellulose } \\
& I_{a m}=\text { The intensity of the background scatters at } \\
& 2 \theta
\end{aligned}
$$

The percentage of crystallinity index for each sample with different particle size is tabulated in Table 1. It can be concluded that the crystallinity index of Leucaena increased as the particle size increased.

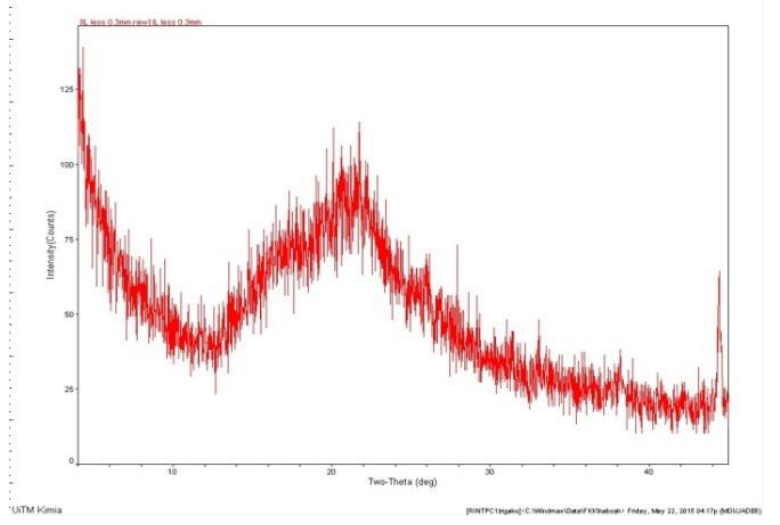

a) Less than $0.3 \mathrm{~mm}$

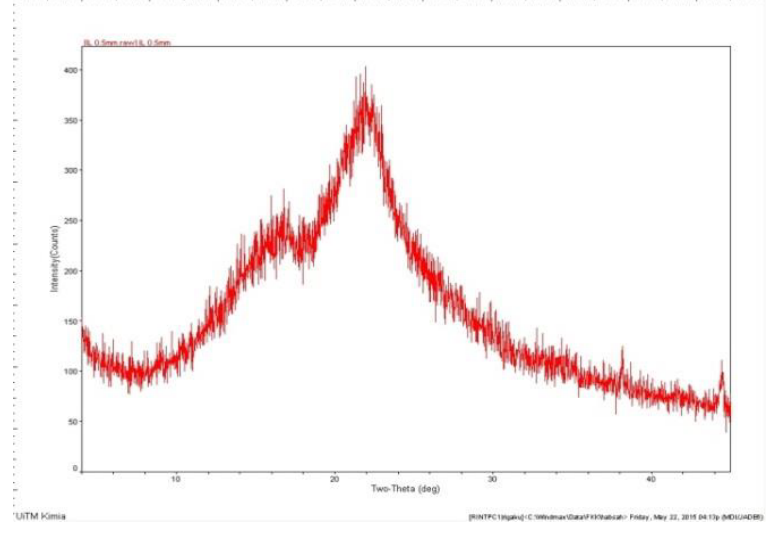

b) $0.5 \mathrm{~mm}$

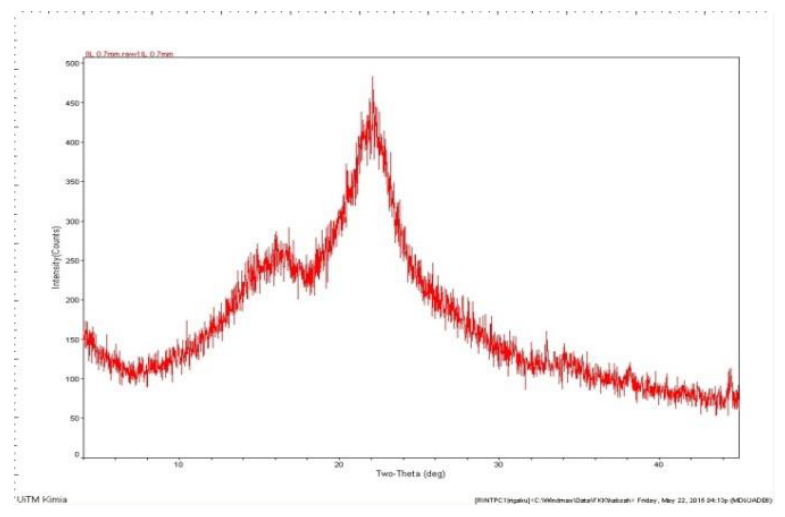

c) $0.7 \mathrm{~mm}$

Figure 1. XRD analysis with various particle sizes.

\subsubsection{SEM analysis (ionic liquid treatment for different particle size)}

Fig. 2 shows the SEM analyzed pictures of untreated and pretreated of leucaena with IL for different particle size. It can be seen that the pretreated leucaena with particle size less than $0.3 \mathrm{~mm}$ has a more irregular and destroyed surface compared to the pretreated leucaena with particle size $0.5 \mathrm{~mm}$ and $0.7 \mathrm{~mm}$.

Table 1. Effect of particle size on crystallinity index of the leucaena.

\begin{tabular}{|c|c|}
\hline Particle Size & CrI (\%) \\
\hline Less $0.3 \mathrm{~mm}$ & 48 \\
\hline $0.5 \mathrm{~mm}$ & 54 \\
\hline $0.7 \mathrm{~mm}$ & 57 \\
\hline
\end{tabular}

The particle size of sample is one of the crucial factor in the pretreatment because it will directly impact on the contact and diffusion of chemicals into the complex structure of the sample. From Table 1, XRD analysis shows that the cristallinity index of leucaena increased with increased in particle size. This is because decreased in particle size will increase the contact surface area of the sample during pretreatment; hence decrease the crystallinity of the sample.

SEM analysis structure in Fig. 2 is clearly shows that the treated leucaena presents more porous structure compared to the untreated leucaena. The pretreated leucaena with particle size less than $0.3 \mathrm{~mm}$ has a more irregular and destroyed surface compared to the pretreated leucaena with particle size $0.5 \mathrm{~mm}$ and $0.7 \mathrm{~mm}$. This shows that the smaller the particle size would provide a more accessible surface area to enhance the cellulose hydrolysis.

The result from this experiment shows that smaller particle size will have more advantages since the percentage of glucose conversion will be increased as the particle size of sample decreased.
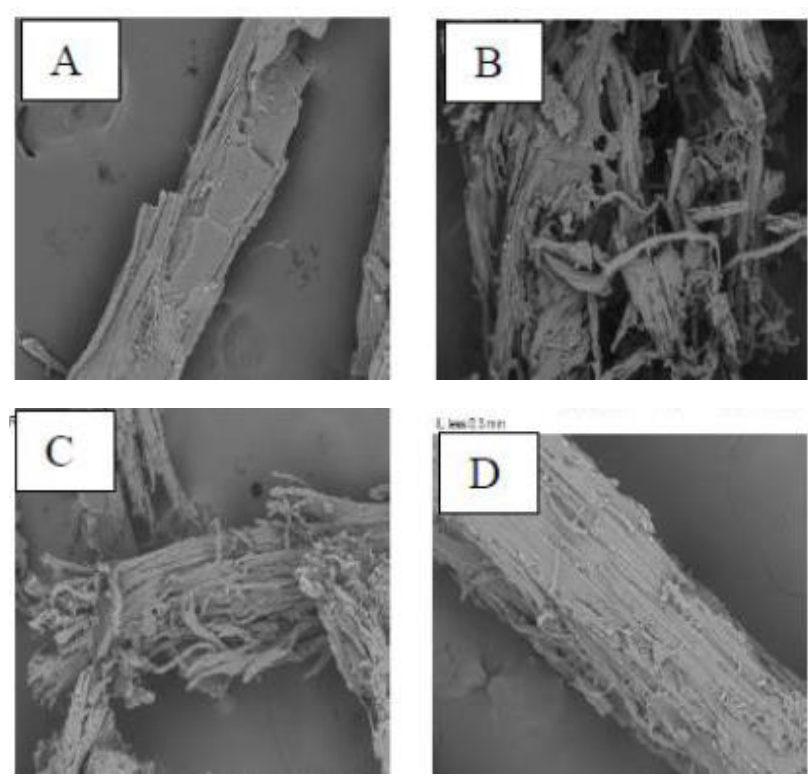

Figure 2. SEM analysis of leucaena (A) untreated, pretreated with IL (B) Less $0.3 \mathrm{~mm}$, (C) $0.5 \mathrm{~mm}$, (D) $0.7 \mathrm{~mm}$. 


\subsection{Effect of different pretreatment temperature on the crystallinity of leucaena}

The crystallinity index by varying the pretreatment temperature was then tabulated in Table 2. It clearly shows that crystallinity index of leucaena decreased as the pretreatment temperature increased. The increased in temperature during pretreatment tend to produce more kinetic energy of the molecule in the sample. Hence, it break down the crystalline structure and decreased the crystallinity of the sample.

Table 2. The effect of temperature on cristallinity index of the leucaena for IL pretreatment.

\begin{tabular}{|c|c|}
\hline Temperature $\left({ }^{\circ} \mathrm{C}\right)$ & CrI (\%) \\
\hline 30 & 63 \\
\hline 60 & 56 \\
\hline 90 & 53 \\
\hline
\end{tabular}

\subsubsection{SEM analysis (ionic liquid treatment for different temperature)}

Fig. 3 shows the SEM analysis while Fig. 4 presents XRD analysis for untreated and pretreated of leucaena with IL for various pretreatment temperature. It can be seen that the increased in pretreatment temperature resulted in more irregular, porous structure and destroyed surface of leucaena. This shows that the higher pretreatment temperature would cause more accessible surface area to enhance the cellulose hydrolysis.
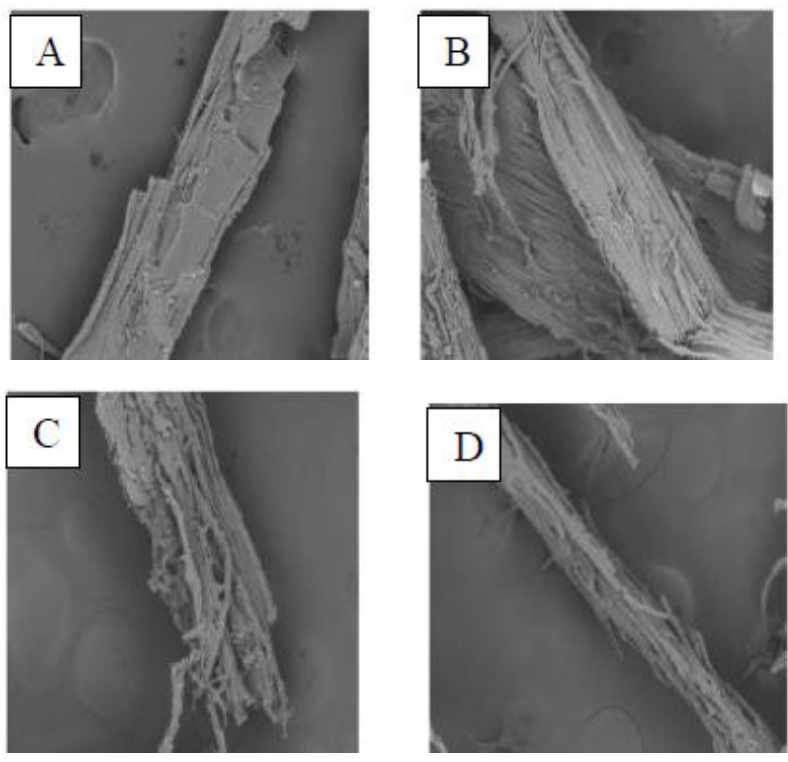

Figure 3. SEM analysis of leucaena (A) Untreated, pretreated with IL (B) $30^{\circ} \mathrm{C}$, (C) $60^{\circ} \mathrm{C}$, (D) $90^{\circ} \mathrm{C}$.

\subsection{Comparison of ionic liquid and ammonia pretreatment}

IL and ammonia pretreatment shows the same result to the crystallinity of leucaena by using different particle size of sample whereby the crystallinity index for both pretreatment increased as the particle size increased. However, in order to determine which pretreatment method is more efficient between IL and ammonia, the comparison test was conducted.

In this experiment, the particle size, temperature and time were set to constant value. The particle size of the sample used was $0.5 \mathrm{~mm}$, the pretreatment temperature at $30^{\circ} \mathrm{C}$ and pretreatment time was 3 hours.

Table 3 tabulates the percentage cristallinity index for ionic liquid and ammonia pretreatment. It shows that the crystallinity index of IL pretreatment was lower than ammonia pretreatment. Thus, IL pretreatment is slightly efficient compared to the ammonia pretreatment for leucaena.

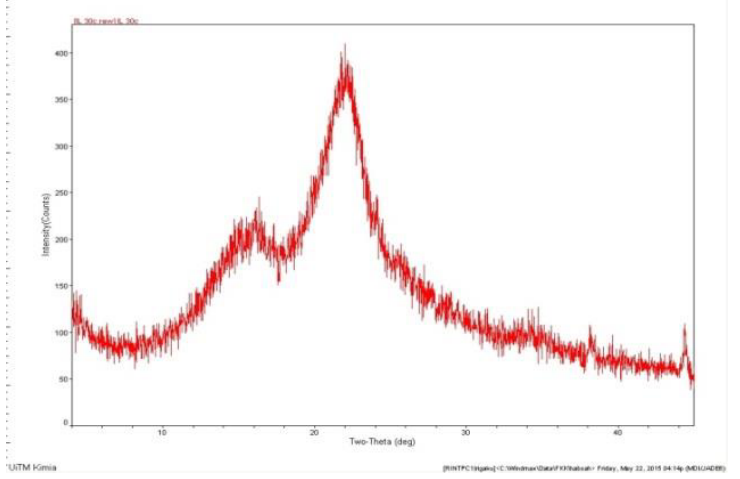

a) $30^{\circ} \mathrm{C}$

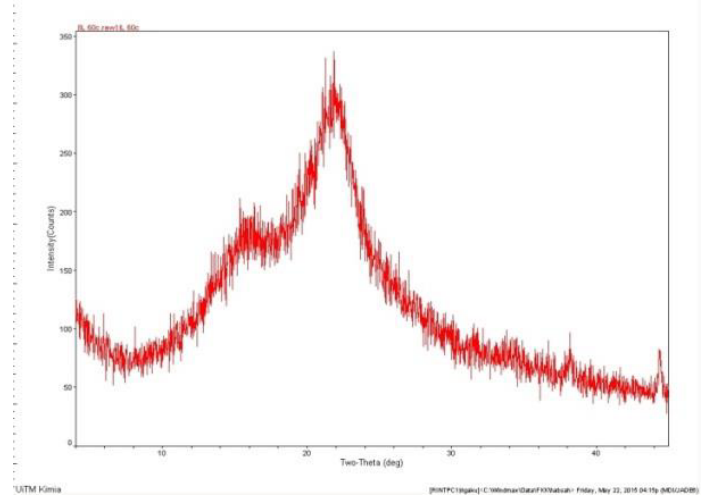

b) $60^{\circ} \mathrm{C}$

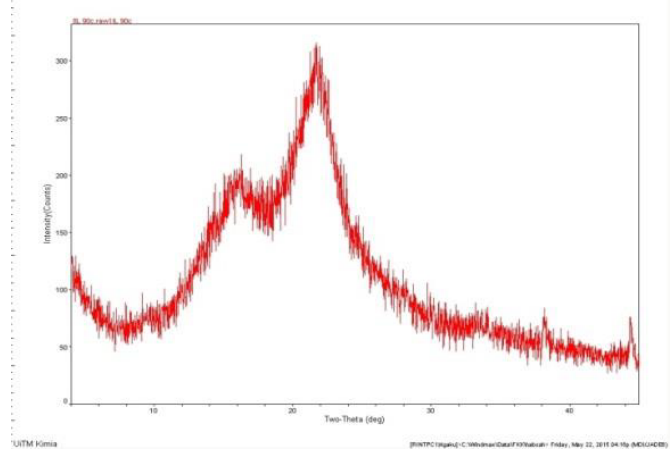

c) $90^{\circ} \mathrm{C}$

Figure 4. XRD analysis for untreated and ILtreated lucaena with various pretreatment temperate.

In conclusion, the pretreatment temperature and 
particle size of the sample have a significant effect on crystallinity of leucaena. The increased in pretreatment temperature causes the crystallinity index of sample decreased. This is due to the changes in kinetic energy of the molecule whicht also increased. Besides, increased in pretreatment temperature will accelerate the dissolution rates of hydrogen bond in the cellulose. In term of particle size, the crystallinity index of leucaena increased as the particle size increased. It shows that smaller particle size will give more advantages to the cellulose hydrolysis. As the particle size of the sample decreased, the contact surface area and diffusion of IL into the complex structure of the sample will increase

Table 3. The effect of cristallinity index for ionic liquid and ammonia pretreatment.

\begin{tabular}{|c|c|}
\hline Pretreatment & Cristallinity Index (\%) \\
\hline IL & 63 \\
\hline Ammonia & 64 \\
\hline
\end{tabular}

\section{Acknowledgement}

This work is supported via financial fund namely the Fundamental Research Grant Scheme (FRGS) 600RMI/FRGS 5/3 (32/2013) by the Ministry of Higher Education Malaysia and also from Universiti Teknologi MARA, Shah Alam, Malaysia.

\section{References}

1. Zhaohui Tong, Pratap Pullammanappallil and Arthur A. Teixeira (2012). How Ethanol is Made from Cellulosic Biomass. University of Florida IFAS Extension. 1-4.

2. Eric M. White (2010). Woody Biomass for Bioenergy and Biofuels in the United States-A Briefing Paper. General Technical Report. PNW-
GTR-825. Portland: U. S. Department of Agriculture, Forest service, Pacific Northwest Research Station. $1-45$.

3. Yang CY, Fang TJ. Combination of ultrasonic irradiation with ionic liquid pretreatment for cellulase hydrolysis of rice straw. Bioresour Technol 2014;164:198-202.

4. Dadi AP, Schall CA, Varanasi S. Mitigation of cellulose recalcitrance to cellulose hydrolysis by ionic liquid pretreatment. Appl Biochem Biotechnol 2007;137-140(1-12):407-21.

5. Jacobs A, Palm M, Zacchi G, Dahlman O. Isolation and characterization of water-soluble hemicelluloses from flax shive. Carbohyd Res 2003;338:1869-76.

6. Chen WH, Kuo PC. Torrefaction and co-torrefaction characterization of hemicellulose, cellulose and lignin as well as torrefaction of some basic constituents in biomass. Energy 2011;36(2):803-11.

7. Tan HT, Lee KT. Understanding the impact of ionic liquid pretreatment on biomass and cellulase hydrolysis. Chem Eng J 2012;183:448-58.

8. Sun SN, Li MF, Yuan TQ, Xu F, Sun RC. Effect of ionic liquid/organic solvent pretreatment on the cellulase hydrolysis of corncob for bioethanol production. Ind Crops Prod 2013;43:570-7.

9. Zenghui Qiu, Giovanna M. Aita and Michelle S. Walker (2012) Effect of ionic liquid pretreatment on the chemical composition, structure and enzymatic hydrolysis of energy cane bagasse. Bioresouce Technology 117: 251-256.

10. Aderibigbe S. A., Adetunji O. A. and Odeniyi M. A. (2011) Antimicrobial and Pharmaceutical Properties of The Seed Oil of Leucaena leucocephala (Lam.) De Wit (Leguminosae). African Journal of Biomedical Research 14: 63-68.

11. Francesca Lionetto, Roberta Del Sole, Donato Cannoletta, Giuseppe Vasapollo and Alfonso Maffezzoli (2012) Monitoring Wood Degradation during Weathering by Cellulose Crystallinity. Materials 2012, 5,: 1910-1922. 